\title{
THE ATTRIBUTES OF EMOTIONAL INTELLIGENCE AND ITS IMPACT ON ACADEMIC PERFORMANCE
}

\author{
Zeinab Shawky Younis, the British University in Egypt, Egypt
}

dx.doi.org/10.18374//JBR-19-3.3

\begin{abstract}
There is a debate of whether Emotional Intelligence is born or made when it comes to the field of higher education and students 'academic performance The question that arises is: whether students should build on their practical and analytical knowledge transferred by theory only or they should acquire more Emotional Intelligence skills? The new paradigm of thinking encompasses creative and Emotional Intelligence as essential building blocks in most organisations. The current competitive environment implies on students to perform multiple tasks with efficiency and effectiveness, their academic knowledge and theory only will not help facing challenges but their right attitude and Emotional Intelligence towards circumstances will definitely be the added value needed for them to face complexities of life. These skills help to lead with impact for a future generation able to combine the Intellectual intelligence (IQ), inherited capacity which enables cognitive skills to be learned and the Emotional Intelligence (EI) not only as a concept or theory learned but as an agile tool applied for leveraging the standards of academic achievement. El is a supplement in this sense to both Analytical and Practical intelligence. The underlying assumption of this research in hand is advocating that if academic performance deals with ambiguity and challenge, therefore Emotional Intelligence -whether inherited traits or acquired skills- is needed for a student to excel academically. On the academic level, this paper aims at identifying the effect of Emotional Intelligence on students' academic performance in British education system. It will enable further and wider research in the field of education to deliver more findings on a more comparative scale. The information might be of interest to elaborate on more private as well as public higher education institutions as the survey will only include students from the Business department in the BAEPS faculty at the British university in Egypt. On the practical level, in the wave of Educational reform in Egypt and under the umbrella of 2030 strategy it is crucial to run such study to clarify the impact of El on the quality of academic achievement for students and to encourage all educational institutions to enhance these skills to increase their students' academic performance. The research could be upgraded to be applied on the business sector institutions in the field of business in general as today organisations are looking for employees - who are the future graduate students- who have the necessary knowledge as well as skills to deal with challenging situations.
\end{abstract}

Keywords: Emotional Intelligence (EI), Social intelligence, Self-awareness, self-regulation, selfmanagement, Triarchic Theory of intelligence, creative intelligence, lateral thinking, emotional Quotient, empathy, academic achievement, emotional power, Social faci 